\title{
STRUCTURAL AND DURABILITY ANALYSIS OF A NOVEL RE-ROOFING CONCEPT
}

\author{
Russell RICHMANa, Evan BENTZ' ${ }^{\mathrm{b}}$, Denver JERMYNª, Chang SUN ${ }^{\mathrm{b}}$ \\ ${ }^{a}$ Ryerson University, 350 Victoria Street, Toronto, ON M5B 2K3, Canada \\ ${ }^{b}$ University of Toronto, 563 Spadina Crescent, Toronto, ON M5S 2J7, Canada
}

Received 19 June 2017; accepted 12 October 2017

\begin{abstract}
Metal roof decks in long-span light steel structures can become damaged and obsolete by corrosion should the roofing system become compromised. Re-roofing is conducted by either removing and replacing damaged areas (resulting in suspension of interior operations and lost revenue) or installing new decking directly over the damaged areas which can transfer corrosion to the new deck. This research conducts structural and durability analyses on a novel proposed re-roofing concept that installs a new metal roof deck over the existing deck by using a proprietary deck strap resulting in no interruption of interior processes. Preliminary structural analysis shows the proposed concept to be applicable to generic conditions around Southern Ontario. Recommendations for project specific structural analysis are made. Durability analysis demonstrates that the proposed concept system improves hygrothermal performance of the roof assembly in all cases except when insulation in the existing roof assembly is saturated. Saturated insulation should be removed prior to installing the re-roofing system.
\end{abstract}

Keywords: metal roof deck, corrosion mitigation, flat and low-slope roofing, roof replacement, re-roofing, reduction in loss of downtime, roof retrofit application, structural analysis, durability analysis, hygrothermal performance.

\section{Introduction}

The use of steel roof decks on flat or low-slope roofing typically found in warehouse and long-span light steel structures is intended to perform four primary functions: (i) load distribution, (ii) lateral support (structural diaphragm), (iii) roof assembly support (membrane, insulation, etc.) and (iv) provide fire protection for the roof assembly. A compromise in the roof membrane can result in deterioration of the steel roof deck. Once the steel decking is corroded, its primary functions are compromised and the deck must be reinstated.

To date, reinstatement has been achieved by (i) removing and replacing areas of damaged decking or (ii) installing new decking directly over the damaged areas; both involve a varying degree of roof assembly replacement. Further, and possibly the largest financial concern for some buildings, removal of corroded decking typically suspends all interior operations (i.e. loss of revenue) for relatively long periods of time due to hazardous conditions and risks during the process. The installation of new decking directly over the compromised areas typically results in the transfer of corrosion between the old and new decking. Therefore it would be advantageous to provide a re-roofing system that can be installed without completely removing the existing roofing system and without propagating corrosion to the new decking.

This paper focuses on a novel concept to install a new metal deck and roof assembly above existing areas of deteriorated metal decking with little or no inter- 
ruption to interior processes (i.e. no loss of revenue). The process comprises a plurality of deck straps used to structurally bridge the new roof deck/assembly to the top of the main open-web steel joist system typically found in the warehouse building typology.

Two separate installation methods of the proposed concept are possible. Installation Method 1 involves the complete removal of the existing roof system waterproofing and insulation layers leaving only the existing metal roof deck. Installation Method 2 involves a partial removal of the existing roof system waterproofing and insulation layers along the open web steel joists, leaving the majority of the existing roof assembly undisturbed. In both methods, deck straps are then fastened to the existing roof deck at existing open web steel joists. A new roof deck is fastened to the deck straps and new insulation and waterproofing layers are applied. It should be noted that the dimensions of the deck strap differ between Installation Method 1 and 2 as clearance must be left to accommodate the thickness of the remaining roof assembly present in Installation Method 2, resulting in a taller deck strap.

For either installation method, two orientations are possible depending on the extent of corrosion of the existing roof deck. The re-roofing method could be applied to the entire roof area terminating at the parapet walls or roof edge or the re-roofing method could be applied in strips that span from one end of the roof to the other, but do not cover the entire roof area. In the second orientation, cant strips would be applied to address the elevation difference between the reroofed and original portions of the roof. Additionally, roof drains, chimneys, and other penetrations would be extended to accommodate the new roof elevation and to avoid any changes to roof drainage patterns and interior duct or pipe routing.

This paper presents the results of structural and durability (hygrothermal) analyses to evaluate various aspects of performance of the re-roofing system, including structural behaviour under various load conditions and the system's ability to manage moisture both from the exterior and residual from the original failed assemblies.

\section{Literature review}

The North American commercial roofing materials market alone was estimated at $\$ 5.9$ billion in 2014 (BCC Research 2015). Although the cost of roof mate- rials and the labour to replace assemblies is high, the cost of service disruption below is even greater. Few researchers have attempted to quantify the cost associated with disruption; however Wallace and Rossiter (1998) note the cost and associated risk to be very high. Lounis et al. (1998) further highlight the risk by advocating for service life prediction and thus, preventative roof replacement strategies. The proposed concept has the ability to replace compromised roof systems while leaving the original roofing intact and thus minimizes or eliminates disruptions below.

Before prototyping the proposed concept, it is important to understand the loading implications associated with adding an additional roof assembly, in addition to regional changes in snow loading from a building's original year of construction to that at the time of roof replacement. Many studies have focussed on roof loading and highlight the importance of understanding changes associated with building design, site anomalies, and weather trends (Stathopoulos, Luchian 1990; Taylor 1992; Irwin et al. 1995; Kennedy et al. 1985).

The concerns relating to the durability of lowslope roof assemblies and management of replacement and/or repairs has been studied greatly (Rudbeck 2001; Lounis, Vanier 2000; Xing, Taylor 2011; Marques et al. 2011; Choi et al. 2012; Dong et al. 2005; Costello 2011). Hygrothermal analysis of new roofing strategies is essential.

\section{Proposed concept and novel deck strap}

The crux of the proposed concept, the deck strap, is shown in Figure 1 outlining key geometrical information.

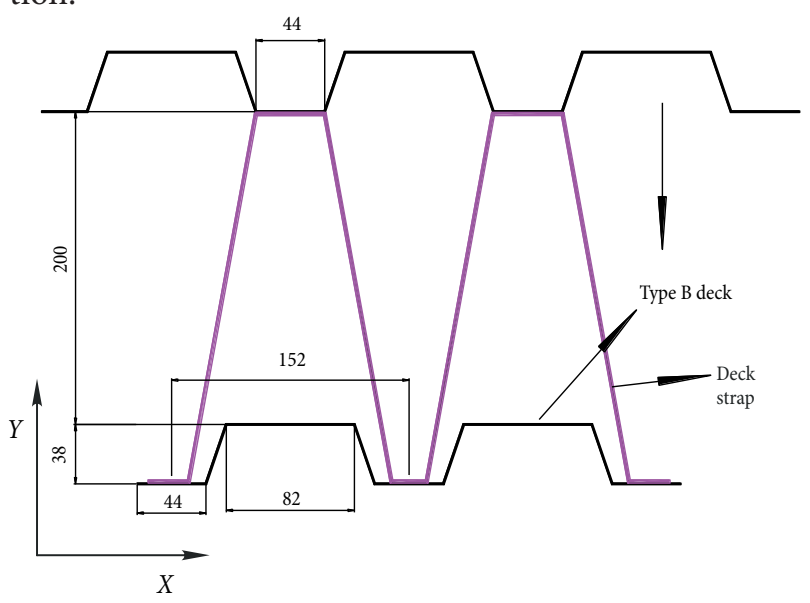

Fig. 1. Schematic of the proposed deck strap (in $\mathrm{mm}$ ) 


\subsection{Design assumptions}

- The $200 \mathrm{~mm}$ dimension of the space between the two decks is variable, meaning it is based on the actual height of the existing roofing and insulation materials of a particular project.

- The height of the existing and new deck is simplified to approximately $40 \mathrm{~mm}$, providing a conservative assumption.

- The length of the lower portion of the strap is also variable within $44 \mathrm{~mm}$. For this work, it was assumed to be $30 \mathrm{~mm}$.

- The thickness of the strap can be gauge 10 $(3.57 \mathrm{~mm})$, gauge $12(2.78 \mathrm{~mm})$, or gauge 14 $(1.98 \mathrm{~mm})$ all of which are commonly used thicknesses in industry, however Gauge 12 $(2.78 \mathrm{~mm})$ was selected for the analysis.

- Based on a primary design of an open web steel joist in Toronto, the width of the deck strap was set to $70 \mathrm{~mm}$ which is just less than the width of the upper chord (double angle L38X38X4.8) of the open web steel joist.

- The material of the deck strap was assumed to be steel that has a yield strength of $300 \mathrm{MPa}$.

\section{Structural analysis}

\subsection{Assumptions}

- Based on typical lengths observed in the field, a sample roof measuring $2 \mathrm{~m}$ by $10 \mathrm{~m}$ was utilized in the analysis.

- The roof decks were assumed to be typical Type B decks (SDI 2015).

- The structure considered in the analysis was assumed to have been built in the 1980's and therefore the roofing and insulation layers are typical of the type found in commercial and industrial construction at that time.

- Dead load includes the self-weight of the open web steel joists, the total weight of the deck and the material thereon, all of the interior finishes that are attached to the ceiling and ducts and fixtures that are installed under the roof. Variation in dead load from structural element sizing is taken into account.

- The scope of this research was limited to southern Ontario (defined as south of the City of Sudbury).

- 1980 loading requirements were from CAN3S16.1-M78 (CSA 1978).
- For current loading CSA S16-09 was used (CSA 2009).

- Based on analysis by Sun (2013), there is no appreciable difference between the wind loads in 1980 compared to that of 2010 .

\subsection{Strap design and analysis}

The minimum design snow load on a roof was designed according to the 1980 National Building Code by multiplying the specified snow load on the ground by the appropriate snow load coefficient applicable to the particular roof area considered (NRC 1980). 1980 and 2010 Snow loads were calculated for 92 total locations. A graphical representation of comparative snow load increases/decreases by city can be found in (Sun 2013). The level of variation for all locations lies within the range of $-0.56 \mathrm{kN} / \mathrm{m}^{2}$ (decrease from 1980 to 2010 ) and $0.64 \mathrm{kN} / \mathrm{m}^{2}$ (increased from 1980 to 2010). No particular trend was observed as a result of this analysis.

All loads were combined to show how the overall loading condition changes when adding the re-roofing system to a 30 year old roof. Both the 1980 and 2010 National Building Codes listed three possible combinations of dead load, snow load, and wind load as outlined in Sun (2013). All of the combinations were calculated and the two controlling cases were found for the year 1980 and 2010 respectively. The difference between these two cases will indicate the suitability of the proposed re-roofing concept for a specific geographic location. Practically, the same calculations could be done for all 92 regions, however four representative locations were chosen in this work.

This analysis shows the importance of location and governing loading when considering the proposed concept for a building. In general, some locations will be restricted to Installation Method 1 which will increase the overall cost of the project (i.e. Huntsville). However, for many locations, the existing roofing will be able to remain (in part or in whole), thus reducing the cost of the proposed concept.

Two kinds of loading conditions were considered to illustrate the behavior of the deck strap: (i) Toronto and (ii) Maximum loading condition using the NBC 2010 (different from that in Section 3.3). Here, the loading calculation for the deck strap is only restricted to the gravity load of the new components supported by the deck strap in addition to 2010 loading requirements. To be conservative, the maximum loading con- 
dition combines all the maximum loading in southern Ontario based on NBC 2010. All the loads acting on the decks were assumed to be uniformly distributed loads and these loads are transferred through the decks to the upper part of the deck straps.

Figure 2a outlines the force calculation of a single span of the deck strap. A span of the deck strap supports a single span of the steel deck which has a tributary area of $2000 \mathrm{~mm}$ by $152 \mathrm{~mm}$. The $2000 \mathrm{~mm}$ is the distance between two adjacent open web steel joists. The $152 \mathrm{~mm}$ is the width of a single span deck for Type B. The total force acting on the deck strap can be obtained by multiplying the calculated controlling load by this tributary area, and then divided by the loading width of the strap $(44 \mathrm{~mm})$ which is the uniformly distributed load acting on the top of the model. Figure $2 \mathrm{a}$ is a schematic diagram because an initial imperfection is considered during calculation. More detailed information will be elaborated below.

In Figure 2a, each number stands for a node, the number in brackets is an element. It was assumed that the lower part of the strap is connected to the joist in the middle, resulting in node 1 and 25 assumed to be rigid. The bottom $15 \mathrm{~mm}$ member was divided into two elements. Because they are supported by the open web steel joist, nodes $2,3,23$, and 24 are not able to move downwards in the y-direction and the boundary condition for them is rotation free and translation free (i.e. a roller). Both the diagonal members were divided into eight elements and the $44 \mathrm{~mm}$ section of the strap was divided into four elements, which makes a total of 24 elements and 25 nodes.

The stiffness of the element on top is variable and difficult to predict. If the deck is cast with concrete on top, the upper element of the strap will deform uniformly in the y-direction. If the deck is extremely soft, the loading condition will be uniformly distributed, which will potentially cause a large moment within the element. Because of this undefined stiffness relationship between the new deck and the upper part of the strap, the real loading condition of the strap is between a loading condition that causes uniform displacement of the upper portion and uniformly distributed load. Calculations were completed for both conditions, and the uniformly distributed load is naturally more critical for the strap. From a conservative perspective, a uniformly distributed load was used for further analysis.

Due to the uniqueness of this structure, both in dimension and loading condition, the analysis was performed based on the classical theory of elasticity.
Also, safety factors were used to evaluate the results. For stress calculations, the safety factor was set equal to 2.0, while for buckling load, the safety factor was taken as 3.0.

\subsection{Maximum loading case}

Figure $2 \mathrm{a} / 2 \mathrm{~b}$ presents the maximum loading case. By using the results in this case and the approach outlined above, stress and shear stress were verified.

Stress of node 11 in element 10 (same for node 15 in element 15):

$$
\begin{aligned}
& \frac{\mathrm{P}}{\mathrm{A}}+\frac{M \cdot y}{I}=\frac{883 \mathrm{~N}}{195 \mathrm{~mm}^{2}}+ \\
& \frac{1653 \mathrm{~N} \cdot \mathrm{mm} \times 1.39 \mathrm{~mm}}{125 \mathrm{~mm}^{4}}=22.9 \mathrm{MPa}< \\
& \frac{f_{y}}{\text { S.F. }}=\frac{300 \mathrm{MPa}}{2}=150 \mathrm{MPa} .
\end{aligned}
$$

Stress of node 13:

$$
\begin{aligned}
& \frac{\mathrm{P}}{\mathrm{A}}+\frac{M \cdot y}{I}=\frac{152 \mathrm{~N}}{195 \mathrm{~mm}^{2}}+ \\
& \frac{7919 \mathrm{~N} \cdot \mathrm{mm} \times 1.39 \mathrm{~mm}}{125 \mathrm{~mm}^{4}}=88.8 \mathrm{MPa} ; \\
& 22.9 \mathrm{MPa}<88.8 \mathrm{MPa}<\frac{f_{y}}{\text { S.F. }}=\frac{300 \mathrm{MPa}}{2.0}=150 \mathrm{MPa} .
\end{aligned}
$$

Shear stress

$$
\begin{aligned}
& \frac{\mathrm{V} \cdot \mathrm{Q}}{\mathrm{I} \cdot \mathrm{B}}=\frac{870 \mathrm{~N} \times 67.6 \mathrm{~mm}^{3}}{125 \mathrm{~mm}^{4} \times 70 \mathrm{~mm}}=6.7 \mathrm{MPa}< \\
& \frac{0.577 f_{y}}{\text { S.F. }}=\frac{0.577 \times 300 \mathrm{MPa}}{2.0}=86.6 \mathrm{MPa} .
\end{aligned}
$$

As can be seen above, this design will not be governed by internal stresses in either case. There is, however another possible controlling condition that required consideration, global buckling.

\subsection{Buckling analysis}

From Figure 2c, the maximum axial force can be found in the diagonal members and from classical stability theory. The critical buckling load can be calculated by:

$$
P_{c r}=\frac{\pi^{2} \cdot E I}{(K \cdot L)^{2}} .
$$

For a defined cross-section, the only variable in this equation is $K \times L$, the effective length. The actual length, $\mathrm{L}$, is a known variable. Therefore, to calculate the critical buckling load, $P_{c r}$, the factor K must be determined. 
a)

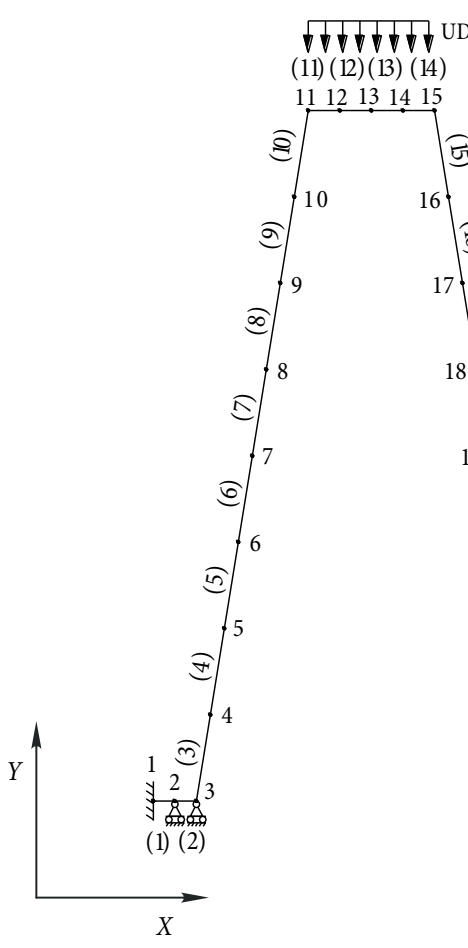

b)

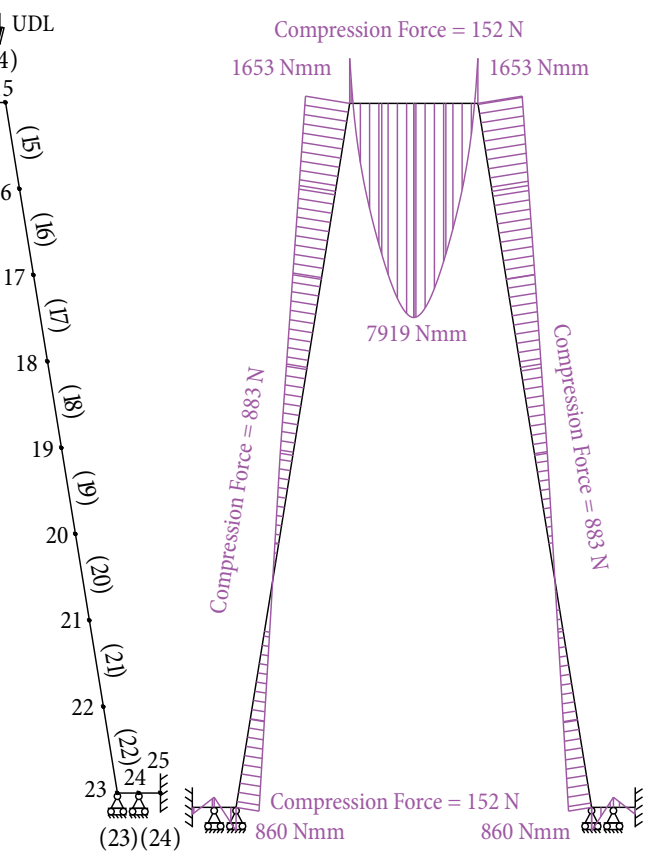

c)

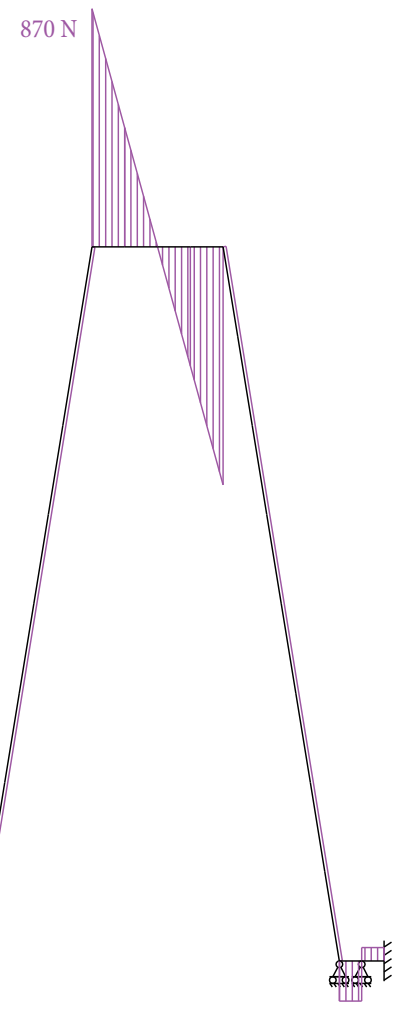

Fig. 2. (a) Schematic calculation model; (b) Bending moment diagram; (c) Axial and sheer force diagram

The $\mathrm{K}$ factor is taken as 1.0 for a column that has pin joints at both ends or taken as 0.5 for a column that has fixed joints at both ends. The diagonal member in question can rotate at both ends, but is also restrained by the horizontal elements at both ends if it starts to rotate. So the $\mathrm{K}$ factor for this member should lie between 0.5 and 1.0.

In Annex G of CSA S16-09 (CSA 2009), there is a recommended method for calculating the $\mathrm{K}$ factor for special columns, "Criteria for estimating effective column lengths in continuous frames". From the first part of the Annex, "this Annex only applies to cases related to buckling, i.e., to axially loaded columns and beam columns failing by out-of-plane buckling"(CSA 2009) ${ }^{1}$. Therefore this method applies to this diagonal member and a suitable value of $\mathrm{K}$ could be obtained by following the method in this Annex.

When the equivalent I/L of adjacent girders which have rigid connections with the column is known, Figure G.1 in this Annex gives a corresponding $\mathrm{K}$ value by drawing a line connecting the values of $G_{U}$ and $G_{L}$ as illustrated in (CSA 2009).

\footnotetext{
${ }^{1}$ Page $1-150$, Handbook of Steel Construction, $10^{\text {th }}$ edition.
}

Because of the variable nature of the height of this diagonal member, the nomograph is not an applicable approach to obtain the K factor. CSA (2009) also offers the equation on which the nomograph is developed along with the definition of $\mathrm{G}$.

$$
\begin{aligned}
& \frac{G_{U} G_{L}}{4}\left(\frac{\pi}{K}\right)^{2}+\frac{G_{U}+G_{L}}{2}\left(1-\frac{\pi / K}{\tan \pi / K}\right)+ \\
& 2\left[\frac{\tan \pi / 2 K}{\pi / K}\right]=1 \quad(*) .
\end{aligned}
$$

Subscripts $\mathrm{U}$ and $\mathrm{L}$ refer to the joints the two ends of the column section being considered and

$$
\mathrm{G}=\frac{\sum I_{c} / L_{c}}{\sum I_{g} / L_{g}},
$$

where: $\Sigma=$ summation for all members rigidly connected to that joint and lying in the plane in which buckling of the column is being considered; $I_{c}=$ moment of inertia of the column about the axes perpendicular to the plane of buckling; $L_{c}=$ unsupported length of a column; $I_{g}=$ moment of inertia of the girder about the axes perpendicular to the plane of buckling; $L_{g}=$ unsupported length of a girder. 
G.5 in (CSA 2009) states a 1.5 or 2.0 modification factor for the girder stiffness for a given boundary condition of the far end of the girders. Both 1.5 and 2.0 will increase the denominator of $G$, and the value of $G$ will be decreased which will lead to a smaller $\mathrm{K}$ value from the nomograph. In this work, this stiffness modification is not used to be conservative. Therefore the stiffness of the column and the girders are the same. The equation for $\mathrm{G}$ is simplified into

$$
G=\frac{L_{g}}{L_{c}} .
$$

The lower joint of the column is connected to the element that is attached to the open web steel joist, and the length of this element is potentially variable. A conservative estimate can be made that $L_{c}$ is set equal to $30 \mathrm{~mm}$ for the lower joint $\mathrm{G}$ calculation. $30 \mathrm{~mm}$ is the total length of the lower element of the strap. Then the calculation of $\mathrm{K}$ shall be started with the calculation of $G_{U}$ and $G_{L}$ (when the clear height between the two decks is taken as $200 \mathrm{~mm}$ ).

$$
\begin{gathered}
G_{U}=\frac{L_{g_{-} U}}{L_{c}}=\frac{44 \mathrm{~mm}}{243 \mathrm{~mm}}=0.181 ; \\
G_{L}=\frac{L_{g_{-} L}}{L_{c}}=\frac{30 \mathrm{~mm}}{243 \mathrm{~mm}}=0.123 .
\end{gathered}
$$

A K value of approximately 0.57 could be determined "at the intersection of the straight line between the appropriate points on the scales for $G_{U}$ and $G_{L}$ with the scale for K". As mentioned, this method will work for a fixed length such as this; however it is not an appropriate approach for the whole analysis. In this case, since the calculation is done by spreadsheet, the strategy is to recalculate the value of $\mathrm{K}$ by iteration.

Under maximum loading condition, when the deck strap height is $200 \mathrm{~mm}$, the maximum compression force in one leg of the strap is $883 \mathrm{~N}$ according to calculation. This force reflects the stress condition of the deck strap when it is in place after construction. During construction, the straps need to be strong enough to endure the construction loads without yielding or buckling. It is conservative to assume that a person's weight should be added into this compression force, as there may be scenarios where a person is walking on the deck while carrying materials. Here, another $1500 \mathrm{~N}$ is added into the compression force and then compared to the critical buckling load. This critical buckling load is calculated by using the information above.
$P_{c r}=\frac{\pi^{2} \cdot E I}{(K \cdot L)^{2}}=\frac{\pi^{2} \times 200000 \mathrm{MPa} \times 125 \mathrm{~mm}^{4}}{(0.572 \times 243 \mathrm{~mm})^{2}} \approx 12.8 \mathrm{kN}$.

The safety factor for buckling load is 3.0, therefore

$$
P_{\max }=883 \mathrm{~N}+1500 \mathrm{~N}=2383 \mathrm{~N}<\frac{P_{c r}}{3}=4270 \mathrm{~N} \text {. }
$$

Therefore, this case is safe under the given assumption.

The same process was repeated for all the other scenarios, including different loading cases and different heights. For each height, the $\mathrm{K}$ value should be recalculated with the given information.

\subsection{Initial imperfection}

During transportation and construction, it is possible for the relatively long diagonal member to be bent into a slightly curved shape. So, an initial imperfection may be formed before the deck strap is loaded. This will cause a series of issues that will raise the possibility of structural failure. Therefore, it is crucial that this factor be considered during calculation. Figure 3 demonstrates a deck strap member with an initial imperfection on both legs. During the frame calculation, it was assumed that the curved element is divided at the middle point of the diagonal member where the biggest deformation locates into two straight lines and then both lines are divided into four elements during calculation, eight elements in total for each member, which is substantially the same as the calculation model in Figure 3.

The effect of initial imperfection on member forces is included in the results and will also influence the buckling condition of the deck strap. Because of imperfections, when a column is loaded there will be an additional moment resulting from the axial load, which will essentially make the loading condition worse. This is similar to the well-known P- $\Delta$ effect (Deierlein et al. 2010; Powell 2010).

There is a standard approach in CSA S16-09 (CSA 2009) to deal with initial imperfections in a frame analysis. A horizontal point load is added to the side of a frame to make the frame sway under load, then, the forces caused by this point load multiplied by a $U_{2}$ factor are added into the original calculation. This horizontal point load is called the "notional load" according to S16-09. The concept of notional loads is an internationally recognized technique for transforming a sway buckling problem into a bending strength problem. 
a)

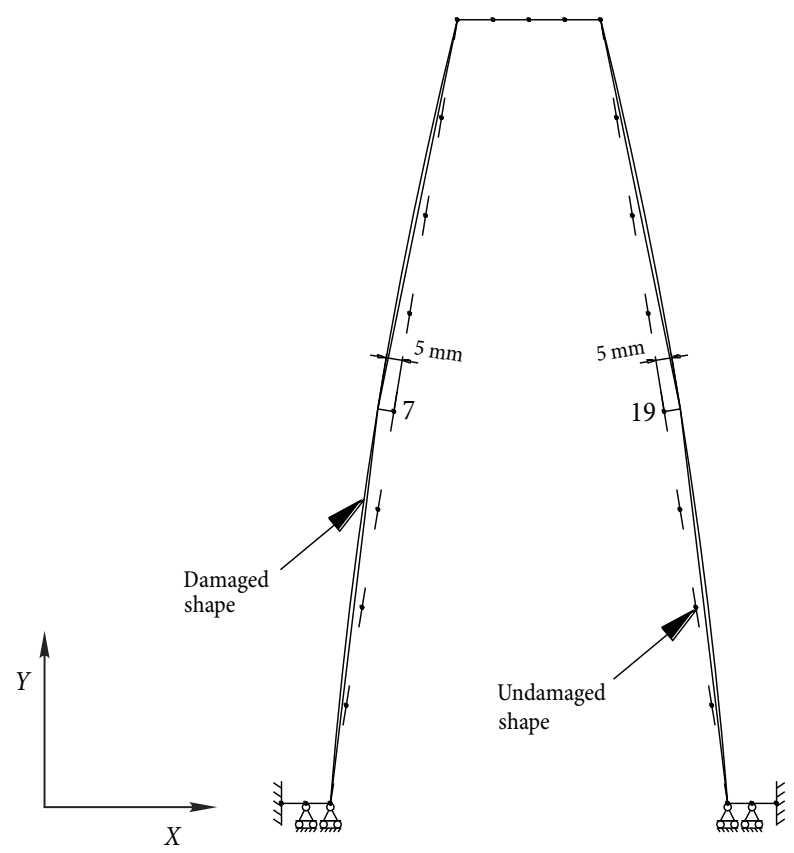

b)

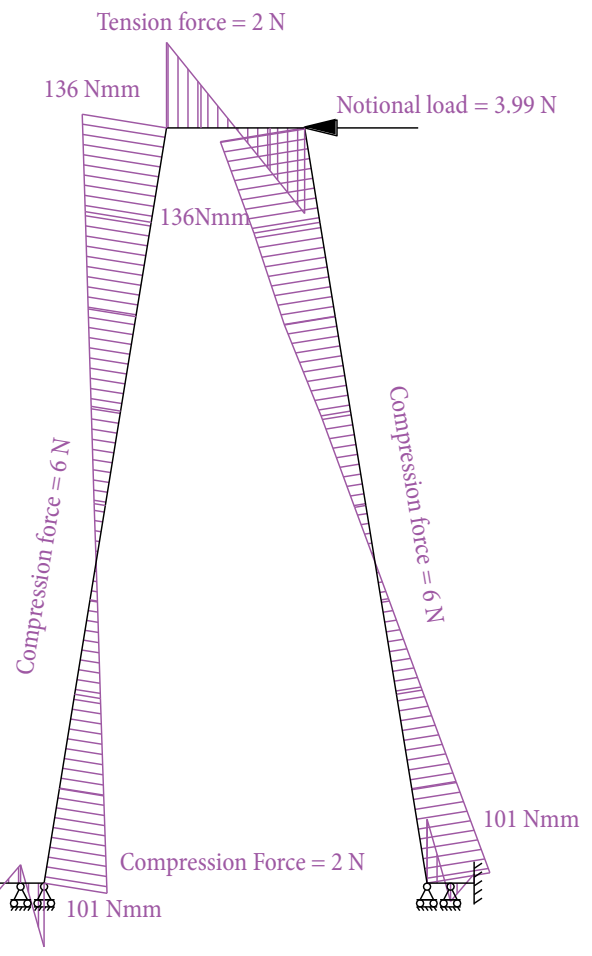

Fig. 3. (a) Sketch of initial imperfection; (b) Bending moment and axial force diagram under notional load for Toronto case

It accounts for the effect of initial imperfections in columns and for partial yielding at factored load levels. Thus, it is applied to all load combinations when the potential for sway buckling exists. Also, it accounts for the P- $\Delta$ moment directly. If effective length factors greater than one were used in the analysis without notional loads, then they can be set to 1.0. Since all the effective length factors here are less than one, this does not have any effect.

For example, consider a deck strap installed in a re-roofing system which requires a $200 \mathrm{~mm}$ clear height and has a loading condition assumed to be the same as Toronto in the previous calculations. The notional load is calculated from the controlling uniformly distributed load in the vertical direction, according to S16-09 Clause 8.4.1.

$$
\begin{aligned}
& \text { Notional Load : } \mathrm{V}=0.005 \times \sum C_{f}= \\
& 0.005 \times 18.1 \mathrm{~N} / \mathrm{mm} \times 44 \mathrm{~mm}=3.99 \mathrm{~N} .
\end{aligned}
$$

The notional load is acting on the same level as the gravity load as can be seen in Figure $3 \mathrm{~b}$. It also includes the bending moment and axial force diagram for this structure under notional load. Calculating the horizontal displacement of the loaded element caused by the total lateral load which, in this case, equals the notional load, $\mathrm{V}$, yields:

$$
\Delta_{f}=0.0277 \mathrm{~mm} \text {. }
$$

The second order effect is contributed by the vertical load acting on its displaced configuration. "Elastic second-order effects may be accounted for by amplifying translational load effects obtained from a first-order elastic analysis by the factor, $U_{2}{ }^{\prime \prime}($ CISC 2014) 2 .

$$
U_{2}=\frac{1}{1-\left[\frac{\sum C_{f} \Delta_{f}}{\sum V_{f} h}\right]}=
$$

The moment of the node 11 in element 10 is increased to

$$
\begin{aligned}
& \mathrm{M}_{\text {Total }}=M_{G}+U_{2} \cdot M_{T}=757 \mathrm{~N} \cdot \mathrm{mm}+ \\
& 1.024 \times 136 \mathrm{~N} \cdot \mathrm{mm}=896 \mathrm{~N} \cdot \mathrm{mm}
\end{aligned}
$$

Also, the maximum compression force is raised from $405 \mathrm{~N}$ to $411 \mathrm{~N}$, which is still safe based on

$$
\begin{aligned}
& \mathrm{P}_{\text {Total }}=P_{G}+U_{2} \cdot M_{T}+1500 \mathrm{~N}= \\
& 404.6 \mathrm{~N}+1.024 \times 6.4 \mathrm{~N}+1500 \mathrm{~N}=1911 \mathrm{~N}< \\
& \frac{P_{c r}}{3}=4270 \mathrm{~N} .
\end{aligned}
$$

${ }^{2}$ Page 1-22, Clause 8.4.2, Handbook of Steel Construction, $10^{\text {th }}$ edition. 
Note that the loading condition does not affect the critical buckling load for the same strap design; therefore the critical buckling load here is the same as the one calculated previously.

In conclusion, the notional load has a very limited effect with slight increases in the results. This design is still safe after the notional load is included in the calculations.

\section{Hygrothermal analysis}

Combined heat and moisture (hygrothermal) analysis of the proposed concept was conducted to: (i) determine the hygrothermal performance under various exterior and interior heat and moisture loads, (ii) determine the differences in hygrothermal performance between the two installation methods, (iii) observe the impact of "punch-through" corrosion of existing roof decks by modelling various air exchange rates, and (iv) observe the impacts of saturated insulation in existing roof assemblies that remain after re-roofing.

Hygrothermal analysis was conducted using both WUFI PRO 5.2 (one dimensional) and WUFI 2D 3.3 (two dimensional) software (Fraunhofer Institute 2015). Base case simulations were conducted for typical flat roof assemblies followed by multiple cases for both installation methods of the proposed concept. Climate data for Toronto (ON) was used in all cases.

One dimensional analysis used the following cases:

- Base: existing roof assembly with no deterioration; default average moisture load; 3 year modelling duration.

- Five test cases for Installation Method 1. The cases were repeated three times for high, medium, and low moisture loads for 3 and 10 year durations:

o Case 1: Re-roofed assembly through the deck strap

o Case 2: Re-roofed assembly, clear roof

o Case 3: Clear roof with $1 \mathrm{ACH}$ air exchange (minimal through-deck corrosion)

o Case 4: Clear roof with $10 \mathrm{ACH}$ air exchange (medium corrosion)

o Case 5: Clear roof with $100 \mathrm{ACH}$ air exchange (significant corrosion)

- Nine test cases for Installation Method 2. Cases 6-9 were simulated with the relative humidity of the existing roof insulation near $100 \%$ to model the effect of saturated insulation on the hygrothermal performance of the re-roofed assembly:

o Cases 1 through 5: Identical to cases 1-5 above

o Case 6: Saturated insulation, $0 \mathrm{ACH}$

o Case 7: Saturated insulation, $1 \mathrm{ACH}$

o Case 8: Saturated insulation, $10 \mathrm{ACH}$

o Case 9: Saturated insulation, $100 \mathrm{ACH}$

Two-dimensional analysis used the following cases:

- Base: existing roof assembly; no deterioration; default medium moisture load; two year modelling duration.

- Installation Method 1: two year duration; medium moisture load. WUFI 2D 3.3 is not capable of modelling air exchange sources and therefore modelling the effects of various corrosion levels of the deck was not possible.

- Two trials were simulated for Installation Method 2:

o Case 1: two year duration; medium moisture load.

o Case 2: Case 1 with saturated insulation.

The results of the hygrothermal analysis are summarized by the number of hours that wooden elements in the assembly (e.g. sheathing, cover board) were at risk of condensation and decay over the simulation period as wood is the most susceptible to moisture damage and deterioration (Johansson et al. 2012; Hannu, Viitanen 1997; Carll et al. 2007; Hukka, Viitanen 1999). For the purposes of this research the assemblies will be considered to be subject to condensation when the relative humidity of the wooden elements meets or surpasses $80 \%$ (Allinson, Hall 2010). The assemblies will be considered to be at risk of decay when the water content of the wood elements meets or surpasses $16 \%$, corresponding to $50 \mathrm{~kg} / \mathrm{m}^{3}$ (Carll et al. 2007). While the wooden members of the assembly are not structural members, their deterioration poses concerns from an energy standpoint (degraded insulation resulting in greater heat loss), as well as from a structural standpoint as moisture laden insulation or cover board can cause corrosion to the steel roof structure due to direct moisture contact or increased humidity in the assembly. Additionally, increased moisture levels in the assembly can cause premature deterioration of the roof membrane (blistering and ridging for example) leading to more frequent maintenance and/or a reduced life span. 


\subsection{One dimensional hygrothermal results}

Figure 4 presents the condensation and decay hours for Installation Method 1. The re-roofed assemblies applying Installation Method 1 show fewer condensation hours than the Base Case and zero decay hours. Fewer condensation hours were even noted in the Medium Moisture Load trials which utilized a 10 year modelling period compared to the three year modelling period of the base case. In all cases Installation Method 1 indicates improved hygrothermal performance compared to the base case.

Figure 5 presents the condensation and decay hours for Installation Method 2 with medium, low, and high moisture loads. Using Installation Method 2 generally results in fewer condensation hours than the Base Case in Cases 1-4 and greater condensation hours than the base case in Cases 5-9. This indicates some improvement in hygrothermal performance for the re-roofed assemblies as long as moisture is not stored in the existing insulation of the assembly. Significantly greater condensation hours were present in Cases 5-9, which represent the saturated insulation cases. The reason for this is that moisture stored in the existing insulation is absorbed and stored into the inner wood fibre cover board. This moisture is then not able to dry out over the course of the modelling period, leading to large periods of time when the relative humidity of the wood fibreboard is in excess of $80 \%$.

With respect to decay potential, the assemblies tend to experience slightly fewer decay hours compared to the Base Case as long as no moisture is stored in the existing insulation. The decay hours of the saturated insulation cases (Cases 5-9) were significantly greater than the Base Case. This highlights the fact that any saturated areas of roofing require full replacement prior to installing the deck straps.

\subsection{Two dimensional hygrothermal results}

Figure 6 reports the condensation and decay hours for both installation methods. The number of condensation hours experienced in the wood cover board of the re-roofed assemblies tended to be less than that of the base case in the two dimensional analysis. The reroofed assembly applied using Installation Method 1 reduced the overall condensation hours compared to the base case. The re-roofed assembly applied using Installation Method 2 resulted in fewer condensation hours for the cover board of the new roof assembly (outer cover board), but resulted in greater condensation hours in the existing cover boards (inner cover board). The increase in condensation hours is greatest for the saturated insulation case, as moisture from the insulation is absorbed into the cover board and is not able to dry out of the assembly.

With respect to decay potential, the number of decay hours in the re-roofed assemblies was fewer than the base case in all cases except the saturated insulation case. Again, the moisture contained in the insulation is absorbed by the inner cover board driving the moisture content above the critical threshold of $16 \%$ and the cover board is not able to dry below the threshold during the modelling period.

\subsection{Summary of hygrothermal analysis}

Hygrothermal analysis typically showed overall drying trends when using the proposed concept. Initial moisture contained in the materials of the new roof assemblies at the time of installation (e.g. construction moisture) was observed to rapidly dry out except in cases where saturated existing insulation was present as a result of a significant roofing failure.

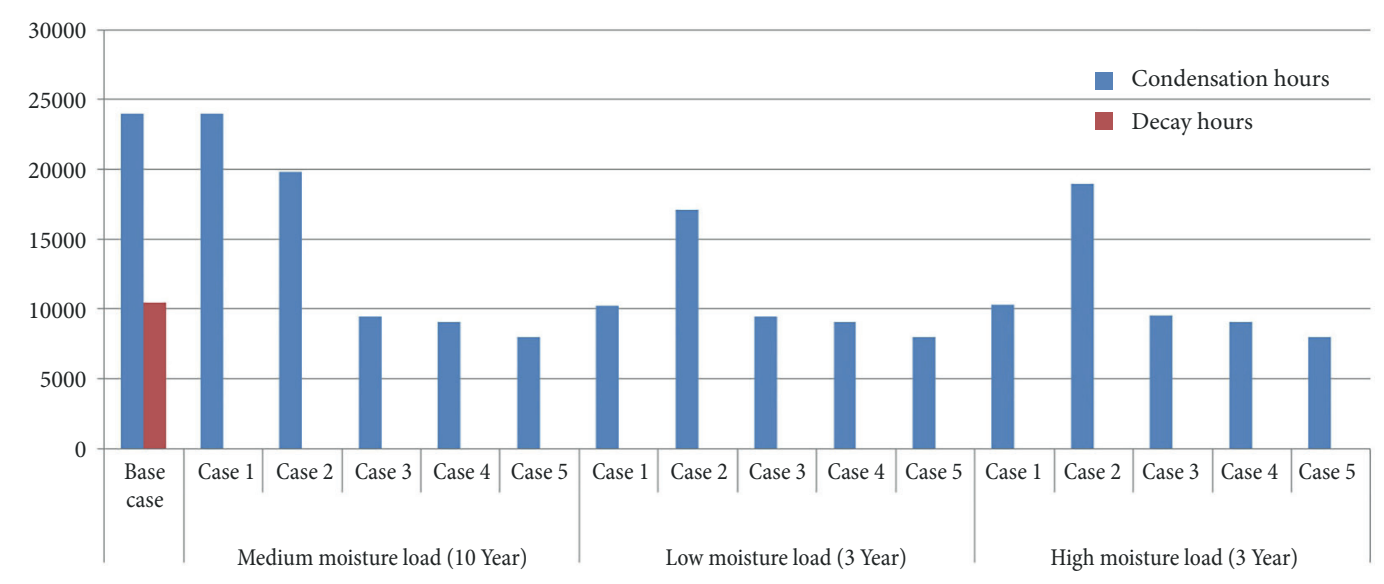

Fig. 4. Condensation and decay hours for installation Method 1 


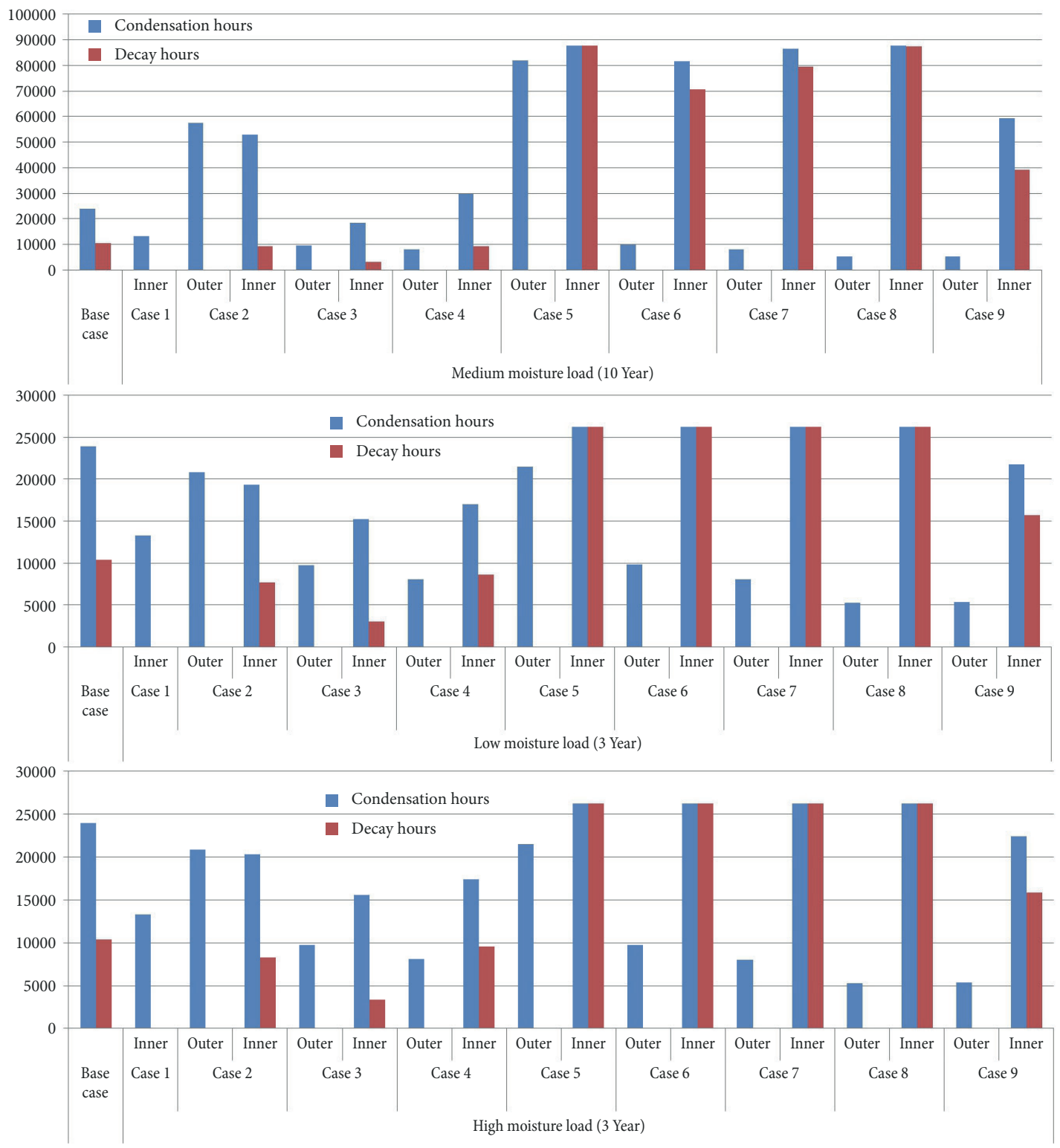

Fig. 5. Condensation and decay hours for installation Method 2 for various moisture loads

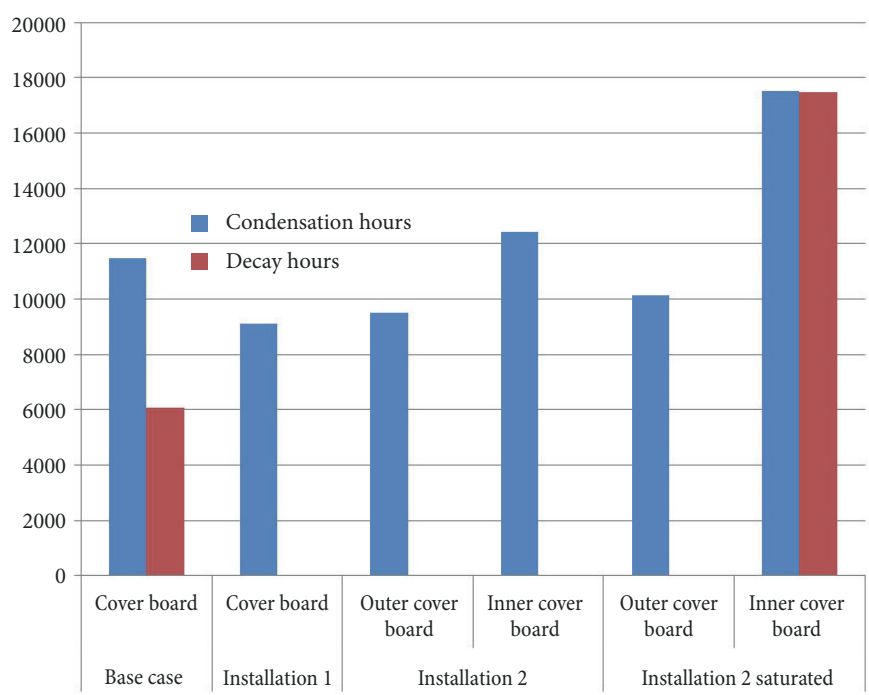

Fig. 6. Two dimensional results for condensation and decay hours 
In all cases, new roof assemblies installed using Method 1 showed improvements in hygrothermal performance compared to the base case. All cases analyzing Installation Method 1 resulted in fewer condensation hours and decay hours than the base case indicating low risk of deterioration and decay. This can likely be attributed to the buffering effects of the additional roof deck and air space beneath the re-roofed assembly.

The cases analyzing Installation Method 2 demonstrated more varied results. The re-roofed assemblies applying Method 2 generally showed improvements over the base case in terms of condensation and decay hours for both the outer and inner cover boards except in the saturated insulation cases. The saturated insulation cases always resulted in significantly greater condensation and decay hours in the inner cover board. The moisture contained in the insulation is absorbed into the inner cover board and is not able to dry out over the course of the modelling periods. As the cover board would be well above the critical relative humidity and moisture content levels over a several year period, damage and deterioration is likely. This indicates that should saturated insulation be present when utilizing the proposed concept, Installation Method 2 is not a viable option, whereas Installation Method 1 appears to be a viable option in all cases explored.

\section{Conclusions}

This research analyzed a novel proposed concept for re-roofing using a deck strap system in order to minimize disturbance to activities within the building and reduce costs associated with roof removal. To examine the general feasibility of the proposed concept, many assumptions have been made in this research. In practice, the proposed concept will require evaluation on a project specific basis as every structure is different and geometrical conditions are of great importance. Based on this research, the location of the building and the year in which it was construction are major factors as some cities are associated with historical increases in snow loads while others with decreased loads. Also, buildings from different time periods may have different design loads based on the standard that was used at the time of construction, even for buildings in the same area.

For the deck strap design, it was found that the strength of the strap is limited by buckling and determining the critical buckling load is vital. For a standard piece of steel (i.e. gauge $12,70 \mathrm{~mm}$ width), the research suggest that the deck strap will perform satisfactorily. Based on theoretical results, experiments need to be done in order to fully understand the behavior of the proposed concept when it has out-of-plane imperfection and when dynamic loads are applied. The notional load approach could be a possible method to deal with imperfections. While the notional load approach is reasonable for taller frames, for example $10 \mathrm{~m}$, in the deck strap case which is $200 \mathrm{~mm}$ tall with a $5 \mathrm{~mm}$ imperfection, the approach is less accurate.

Hygrothermal analysis suggests Installation Method 1 appears to be the preferred installation method as it is typically associated with improved hygrothermal performance compared to the base case. Installation Method 2 only appears to be a viable option when the existing insulation in the roof assembly is not saturated. Care must be exercised in selecting the appropriate installation method and will depend greatly on the specific characteristics of the roof that requires repair. While Installation Method 2 would involve less labour than Installation Method 1, installers must be confident that there is little moisture contained in the existing roof insulation in order to avoid moisture damage and deterioration.

\section{Acknowledgements}

The authors would like to thank RBS Consulting Engineers Ltd. for their assistance and input related to this work. This work is made possible by funding from the Natural Sciences and Engineering Research Council.

\section{References}

Allinson, D.; Hall, M. 2010. Hygrothermal analysis of a stabilised rammed earth test building in the UK, Energy and Buildings 42(6): 845-852.

https://doi.org/10.1016/j.enbuild.2009.12.005

BCC Research. 2015. North American market for commercial roofing materials to be worth $\$ 5.9$ billion in 2014 [online], [cited 25 January 2015]. Available from Internet: http://www. bccresearch.com/pressroom/avm/north-american-marketcommercial-roofing-materials-worth-\$5.9-billion-2014

Canadian Institute of Steel Constructions (CISC). 2014. Handbook of steel construction. $10^{\text {th }}$ ed. Toronto. 2010.

Canadian Standards Association (CSA). 1978. CAN3-S16.1M78 Steel structures for buildings. Limit States Design, Toronto, Canada.

Canadian Standards Association (CSA). 2009. S16 -09 Design of steel structures. Toronto, Canada.

Carll, C.; TenWolde, A.; Munson, R. 2007. Moisture performance of a contemporary wood-frame house operated at design in door humidity levels [online], [cited 10 June 2013]. Available from Internet: http://www.ornl.gov/sci/buildings/2012/Session\%20PDFs/72_New.pdf 
Choi, S.; Oh, S.; Seo, C. 2012. Construction of an evaluation system for selecting an appropriate waterproofing method for the roof of a building, Canadian Journal of Civil Engineering 39(12): 1264-1273. https://doi.org/10.1139/12012-070

Costello, M. 2011. Single ply roofing: introduction to a new sustainability standard for the roofing industry, Journal of ASTM International 8(9): 1-6. https://doi.org/10.1520/JAI103741

Deierlein, G. G.; Reinhorn, A. M.; Willford, M. R. 2010. Nonlinear structural analysis for seismic design, NEHRP Seismic Design Technical Brief No. 4., NIST GCR 10-917-5. Gaithersburg, MD: National Institute of Standards and Technology.

Dong, B.; Kennedy, C.; Pressnail, K. 2005. Comparing life cycle implications of building retrofit and replacement options, Canadian Journal of Civil Engineering 32: 1051-1063. https://doi.org/10.1139/105-061

Fraunhofer Institute [online]. 2015 [cited 29 January 2015]. Available from Internet: http://www.wufi.de/index_e.html

Hannu, A.; Viitanen, H. A. 1997. Modelling the time factor in the development of mould fungi - the effect of critical humidity and temperature conditions on pine and spruce sapwood, Holzforschung 51: 6-14. https://doi.org/10.1515/hfsg.1997.51.1.6

Hukka, A.; Viitanen, H. A. 1999. A mathematical model of mould growth on wooden material, Wood Science and Technology 33(6): 475-485. https://doi.org/10.1007/s002260050131

Irwin, P. A.; Gamble, S. L.; Taylor, D. A. 1995. Effects of roof size, heat transfer, and climate on snow loads: studies for the 1995 NBC, Canadian Journal of Civil Engineering 22(4): 770-784. https://doi.org/10.1139/195-087

Johansson, P.; Ekstrand-Tobin, A.; Svensson, T.; Bok, G. 2012. Laboratory study to determine the critical moisture level for mould growth on building materials, International Biodeterioration and Biodegradation 73: 23-32. https://doi.org/10.1016/j.ibiod.2012.05.014

Kennedy, T. H. R.; Kennedy, D. J. L.; MacGregor, J. G.; Taylor, D. A. 1985. Snow loads in the 1985 National building code of Canada: curved, Canadian Journal of Civil Engineering 12(3): 427-438. https://doi.org/10.1139/185-051
Lounis, Z.; Lacasse, M.; Vanier, D.; Kyle2, B. 1998. Towards standardization of service life prediction of roofing membranes, in Research and Standards Development, 4th Vol., ASTM STP 1349, American Society for Testing and Materials.

Lounis, Z.; Vanier, D. J. 2000. Better performing dryable insulation system for low-slope roofs, Computer-Aided Civil and Infrastructure Engineering 15: 320-329.

https://doi.org/10.1111/0885-9507.00196

Marques, J. A.; Lopes, J. G.; Correia, J. R. 2011. Durability of the adhesion between bituminous coatings and self-protection mineral granules of waterproofing membranes, Construction and Building Materials 25(2011): 138-144.

https://doi.org/10.1016/j.conbuildmat.2010.06.047

National Research Council of Canada (NRC). 1980. National Building Code for Canada 1980. Ottawa.

National Research Council of Canada (NRC). 2010. National Building Code for Canada 2010. Ottawa.

Powell, G. H. 2010. Modeling for structural analysis: behavior and basics. 1st ed. Berkeley, CA: Computers and Structures, Inc.

Rudbeck, D. 2001. Better performing dryable insulation system for low-slope roofs, Journal of Building Physics 24(3): 226239. https://doi.org/10.1106/XKTX-TACU-TEPN-NA79

Stathopoulos, T.; Luchian, H. D. 1990. Wind pressures on buildings with stepped roofs, Canadian Journal of Civil Engineering 17(4): 569-577. https://doi.org/10.1139/190-065

Steel Deck Institute (SDI) [online]. 2015 [cited 22 January 2015]. Available from Internet: http://www.sdi.org/

Sun, C. 2013. Structural analysis of a re-roofing system: Master's Thesis. University of Toronto, Department of Civil Engineering, Toronto, Canada.

Taylor, D. 1992. Snow on two-level flat roofs - measured vs. 1990 NBC load, Canadian Journal of Civil Engineering 19(1): 59-67. https://doi.org/10.1139/192-006

Wallace, T.; Rossiter, W. (Ed.). 1998. Roofing research and standards development. 4th Vol. ASTM, Baltimore, May 1999.

Xing, L.; Taylor, T. 2011. Correlating accelerated laboratory, field, and thermal aging TPO membranes, Journal of ASTM International 8(8): 1-14. https://doi.org/10.1520/JAI103743

Russell RICHMAN. Dr. Richman completed his undergraduate, masters and doctorate degrees at the University of Toronto (Civil Engineer). Dr. Richman has researched in the combined areas of Building Science and Sustainable Buildings since 1998. Dr. Richman heads the Sustainable Buildings Group at Ryerson University. Currently, he is the Program Director of the Graduate Program in Building Science through the Department of Architectural Science. His research interests include: adapting the Passive House standard to North America's climate, development of a Sustainable Renovation Rating Index and quantifying air-tightness in residential dwellings. As a registered professional engineer $(\mathrm{ON})$, Dr. Richman continues to practice, providing expert opinion on a variety of building envelope related projects in Canada and internationally.

Evan BENTZ. Dr. Bentz completed his doctorate degree at the University of Toronto (Civil Engineering). Dr. Bentz is a professor in the Structural Engineering Research Group. His research interests include: Numerical modelling of reinforced concrete behaviour; Technology transfer applications for research on shear and torsion; Service life modelling of reinforced concrete structures; Analysis of ancient structures by modern methods: Response-2000 program; Membrane-2000 program;

Denver JERMYN completed his undergraduate engineering degree in Biological Engineering at the University of Guelph (Ontario, Canada). He is a graduate of the Sustainable Buildings Group at Ryerson University. His research interests include: energy efficient retrofits, building envelope systems, hygrothermal performance and energy modelling. Denver is currently working as an engineer at CDW Engineering (Toronto).

Chang SUN graduated from the Department of Civil Engineering at the University of Toronto. He was part of the structural engineering research group. Chang is currently working as an engineer in China. 